\title{
HIV interactions and the perils of epithelial thinning in the female reproductive tract
}

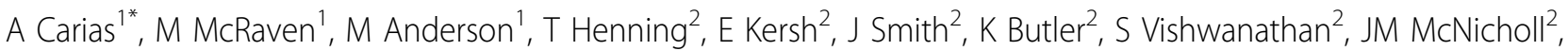 \\ RM Hendry ${ }^{2}$, R Veazey ${ }^{3}$, T Hope $^{1}$
}

From AIDS Vaccine 2012

Boston, MA, USA. 9-12 September 2012

\section{Background}

Currently, there is much debate on whether epithelial thinning from hormonal contraceptives can increase HIV acquisition. Previously, we illustrated that HIV can penetrate to depths in squamous epithelium where it can interact with target cells, such as CD4+ T-cells and macrophages. Using a similar approach, we show that epithelial thinning affects virus penetration, along with target cell and cellular junction distribution.

\section{Methods}

To investigate how genital epithelial thickness may affect HIV penetration, ten female rhesus macaques were pretreated with $30 \mathrm{mg}$ depo-medroxyprogesterone acetate (Depo-provera ${ }^{\circledR}$ ) 4-5 weeks prior to vaginal photoactivatable (PA-GFP) HIV exposure. Additionally, eight female pigtail macaques were exposed to PA-GFP HIV at various menstrual cycle stages. Genital tracts were removed 4 hours post-exposure and immediately dissected and snap frozen in optimal cutting temperature (OCT) compound. Comparison of pre- and post-photoactivation image z-stacks revealed the presence of virus, accounting for background.

\section{Results}

Within 4 hours, PA-GFP virions were observed between squamous epithelial cells penetrating up to depths of $50 \mu \mathrm{m}$. This is within the reach of target cell populations. Furthermore, current analysis illustrated epithelial thickness to be inversely proportional to the number of penetrating virions and target cells, independent of thinning mechanism. Also, cellular junction distribution in pigtail macaques with thinned squamous epithelia mirrored those results of progesterone-treated rhesus macaques.

\section{Conclusion}

Our current results suggest that HIV acquisition in women may be influenced by menstrual cycle and hormonal contraceptives. CD4+ T-cells and CD68+ macrophage distribution and virus penetration were dependent on epithelial thickness, suggesting HIV interactions with female genital epithelia may differ in the luteal and follicular stages of the menstrual cycle. Our results also suggest that progestin-based contraceptives may alter the barrier properties of the stratified squamous epithelium, possibly increasing the risk of HIV acquisition in women.

\section{Author details}

${ }^{1}$ Northwestern University, Chicago, IL, USA. ${ }^{2}$ Center for Disease Control and Prevention, Atlanta, GA, USA. ${ }^{3}$ Tulane National Primate Research Center, Covington, LA, USA.

Published: 13 September 2012

doi:10.1186/1742-4690-9-S2-P363

Cite this article as: Carias et al:: HIV interactions and the perils of epithelial thinning in the female reproductive tract. Retrovirology 2012 9(Suppl 2):P363.

${ }^{1}$ Northwestern University, Chicago, IL, USA

Full list of author information is available at the end of the article

(C) 2012 Carias et al; licensee BioMed Central Ltd. This is an Open Access article distributed under the terms of the Creative Commons Attribution License (http://creativecommons.org/licenses/by/2.0), which permits unrestricted use, distribution, and reproduction in any medium, provided the original work is properly cited. 